\title{
Valuable Innovations out of Nonsense? Expansive Organizational Learning and Transformative Agency in the Mann Gulch Disaster and in the Finnish Homelessness Strategy
}

\author{
Annalisa Sannino \\ University of Tampere, Finland \\ Annalisa.Sannino@uta.fi \\ http://orcid.org/oooo-0003-1470-3666 \\ Yrjö Engeström \\ CRADLE, University of Helsinki, Finland \\ yrjo.engestrom@helsinki.fi \\ http://orcid.org/oooo-0002-6949-4278
}

\begin{abstract}
The study explores the role nonsense may play when innovations are conceived and how innovations out of nonsense possibly inform processes of organizational learning. It argues that an expansive learning and transformative agency framework offers an alternative to primarily retrospective views of organizational sensemaking. The argument in favour of a forward-oriented and materially grounded dialectical perspective builds on two examples of innovations initially conceived as nonsensical and which nevertheless proved to be meaningful and generative: the Mann Gulch disaster and the Finnish national strategy for the eradication of homelessness.
\end{abstract}

Keywords: innovation, organizational learning, transformative agency 
Often highly meaningful organizational innovations are born out of pressing and constraining necessities. Because they break out of existing standards, they may be initially seen as nonsensical. It is therefore not unusual that initiatives toward such innovations are resisted or even discarded at the beginning and reveal their potential only later on. The delayed recognition of the value of such innovations has historically proven to entail high costs for the involved organizations and for the society as a whole. The study presented here offers two examples of cases in which innovations, initially conceived as nonsensical, proved to be meaningful and generative. The study argues that organizational learning processes can benefit from adopting an expansive learning and transformative agency perspective, which offers a forward-oriented and materially grounded dialectical view on innovations. Organizations and societies may this way avoid paying unnecessarily high prices for premature rejection of seemingly "non-sense" initiatives.

Within the frameworks of expansive learning (Engeström, 2015; Engeström \& Sannino, 2010; 2016) and transformative agency (Sannino, 2015; Sannino, Engeström \& Lemos, 2016), innovations can be seen as outcomes of processes in which collectives break out of existing standard practices and construct radically new concepts of the object of their activity, in response to aggravated contradictions and conflicts. This is a kind of organizational learning involving novel undertakings which may initially appear as nonsensical. Also, this learning has a strong transformative and agentive character, which often entails taking risks. Understanding these processes of learning and agency is increasingly important for relating to potentially meaningful innovations in times of crises. The analysis presented here aims at contributing to this understanding by asking: Does nonsense play a role when innovations are conceived? How might innovations out of nonsense inform expansive processes of organizational learning?

The organic link between expansive learning and transformative agency is the red thread of the analysis. The argument builds on a critical consideration of the limits of retrospective sensemaking - a seemingly key contrasting feature between the theory of expansive learning and the theory of organizational sensemaking (Weick, 1995). We will use a classic case from sensemaking theory, namely the Mann Gulch disaster (Weick, 1993), as an intermediate springboard to illuminate the explanatory potential of a forward-oriented perspective on organizational learning afforded by the theoretical lenses of this study. We will then move on to analyze a large-scale organizational learning process, that of the evolution of the Finnish national strategy for the eradication of homelessness. This is a case 
which serves as an example of the importance of a grounded and forward-oriented dialectical perspective on organizational learning. The analysis of this case is necessarily only tentative, as the case is extraordinarily complex, both in terms of the multitude of actors and organizations involved and in terms of the length of the process which started in 2008 and continues today. In spite of the preliminary nature of the analysis, the findings may be used and developed as generative instruments in further studies of complex longitudinal processes of expansive organizational learning.

\section{Sensemaking And Agency}

Sensemaking is not only conceived as an interpretive process. It is conceptualized as "active authoring of events and frameworks for understanding, as people play a role in constructing the very situations they attempt to comprehend" (Maitlis \& Christianson, 2014, p. 58). In this literature, however, action seems not to have specific contours and appears rather as a vague entity subordinated to discourse-centered and retrospective processes of sensemaking.

Sensemaking is often defined as creating rational accounts enabling actions in uncertain or critical situations. In such situations we turn to cues in the environment to try to clarify what is happening. These cues serve as a basis to establish an explanatory account of the events through which we continue enacting the situation. Within this perspective, action stems from the production of such accounts which are discursive constructions of reality (Antaki, 1994; Isabella, 1990; Maitlis, 2005).

Sensemaking is also often seen as a component in the process of construction of consensual and coordinated action: "[S]ensemaking is a way station on the road to a consensually constructed, coordinated system of action.” (Taylor \& Van Every, 2000, p. 275). This perspective tends to lead to strongly logocentric assumptions: "sensemaking involves turning circumstances into a situation that is comprehended explicitly in words and that serves as a springboard for action" (Taylor \& Van Every, 2000, p. 40).

The literature points out that making sense of the world requires acting upon the world and by such actions testing the sense already made and at the same time generating new cues for sensemaking: "The same actions that help people make sense of what is happening can also alter what people encounter and, consequently change the very situation that prompted sensemaking in the first place" (Maitlis \& Christianson, 2014, p. 84). 
The idea of transformative action can be detected in the concept of enactment which refers to the creation by our own action of the environment that we inhabit (Orton, 2000 ; Weick, 1979 , 1988, 1995 , 2003 ; Weick \& al., 2005). Sensemaking, however, is primarily understood also in the classic work of Weick (1995) as a retrospective process consisting in turning back to actions already undertaken. Recent attempts at understanding sensemaking as a prospective movement are helpful for grasping the role of future-oriented actions in sensemaking (Gephart et al., 2010; Kaplan \& Orlikowski, 2013 ; Wiebe, 2010).

It remains unclear, however, how actions materially emerge in these situations. One exception is Whiteman and Cooper's (2011) research which highlights that the sensemaking process comprises the extraction of material cues from the environment, and that attending to such material cues significantly shapes actions in highly equivocal and critical situations.

Literature on crises (Christianson \& Sutcliffe, 2009; Weick, 1988) recognizes what is referred to as dilemmatic or trade-off features of such situations. "On the one hand, hazardous and rapidly unfolding situations are difficult to comprehend, so people want to gather more information to determine the most appropriate action. On the other hand, the demands of the situation often require them to take action with incomplete information." (Maitlis \& Christianson, 2014, p. 93) These dilemmatic or trade-off features are not conceptualized in terms of conflicts.

Here we put forward an alternative conceptualization of the relation between action and sensemaking, seen as materially grounded, future-oriented, and inherently conflictual. In this view, a crucial potential of all human action lies in its inherent orientation toward learning and transformation. This critical quality is thus far largely missing in organizational theories of sensemaking. What follows aims at addressing this gap, by introducing a Vygotskian perspective on transformative agency by double stimulation in some detail. ,Double stimulation has been characterized as a core quality of expansive learning processes (Sannino, Engeström \& Lemos, 2017). This perspective is based on conceptual and experimental work conducted by one of us (Sannino, 2015; Sannino \& Laitinen, 2015).

Vygotsky (1997) describes the emergence of transformative action as a double stimulation process involving two apparatuses which "are relatively independent of each other" (p. 213) and which correspond also to "two stages in the genesis of will" (p. 218). Apparatus 1 consists in deciding to act in a certain way with the help of an auxiliary motive (e.g., the striking of the clock). Apparatus 2 consists in implementing the decision formed in Apparatus 1. Apparatus 1 is the most complex and can essentially be depicted as involving 
conflicts of stimuli, conflict of motives (Fist stimulus), the uptake of an auxiliary motive (Second stimulus), and a closure which consists in sticking to the second stimulus in critical situations which reactivate the conflict of motives.

A conflict of stimuli triggers the formation of Apparatus 1. In the waiting experiment described by Vygotsky (1997), conflicting stimuli can be on the one hand having been asked to wait ("The subject is asked to wait for a long time", Vygotsky, 1997, p. 212) and, on the other hand, finding oneself for "no purpose in an empty room" (p. 212). The experiment is in itself a nonsensical set up, seen by Vygotsky as a setting of transformative outcomes.

The conflict of stimuli activates motives and turns into a conflict of motives. In the waiting experiment two motives may collide: (1) I must stay in this room, (2) I want to leave. Vygotsky (1997) explains that at this point the subject is "exclusively at the mercy of motives" (p. 212). One stimulus is selected and converted into an auxiliary motive or second stimulus. Referring to the person waiting in the empty room, Vygotsky (1997) explains that "the watch instantly constitutes a stimulus that acquires the significance of an auxiliary motive. The subject decides, when the hand of the watch reaches a certain position, I will get up and leave." (p. 212)

This is the core phase of Apparatus 1, in which "the person, using the power of things or stimuli, controls his own behavior (...) makes them serve his own purposes ... He changes the environment with his external activity ...subjecting it to his own authority" (p. 212).

A connection is established between a concretely occurring external stimulus and the decided reaction: "A ... connection between the position of the hands and her leaving" (Vygotsky, 1997, p. 212). In the waiting experiment this phase corresponds to the moment when the clock actually strikes the time when the person intended to leave. When such a direct stimulus occurs the person is confronted with "a signal and a connection with it" (p. 211). The signal is the hand of the clock turning to the given time and the connection is the decision to act in a certain way. This phase seems to be a critical moment in the formation of transformative agency. That is when "the real or actual conflict" (p. 215) of stimuli materially takes place. The closure mechanism is the "closure of the connection between the given stimulus and the reaction" (p. 215).

The implementation of the action in Apparatus 2 can be understood as the execution of an action according to instructions: I leave the room at the signal of the clock hand turning to a certain time. When the closure occurs, the instruction is consolidated to be subsequently followed as if automatically in Apparatus 2. Although it looks like automatic, the action was 
artificially and willfully constructed by the person herself. As such it is the outcome of an intentional process which looks like a strategic plan.

The adoption and use of the second stimulus turns the nonsensical situation into a situation with forward-oriented and transformative potential. In the following the Vygotskian double stimulation framework, seen in its relevance for expansive organizational learning, is used to interpret the Man Gulch case and the case of the Finnish homelessness strategy.

\section{Double Stimulation In The Mann Gulch Disaster}

The Mann Gulch is a case of fire disaster reported and analyzed in the extraordinary book of Norman Maclean, Young Men and Fire (1992). The book and the case it describes were subsequently reanalyzed in a famous Administrative Science Quarterly article by Karl Weick (1993) as a case on interactive disintegration of sensemaking. 13 smokejumpers died in a fire disaster in Montana after having being dropped on what was perceived as a regular fire, but which turned out to be a type of fire never encountered before by a crew in the history of firefighting. The critical events of the disaster are condensed in Figure 1.

\section{How the events evolved}

\section{4:10}

The crew of smokejumpers, including their foreman and a second in command, were dropped with their cargo from 2000 feet on the south side of the Mann Gulch in flames

The crew collected their supplies and ate supper to gain energies for the work ahead, while the second in command and a ranger were scouting around to study the situation. The foreman and the ranger assessed that the thick forest near their landing area could easily turn in a deadly trap.

$5: 10$

In the meantime the crew started to move to surround the fire as this is usually done in these circumstances

When the foreman returned he told the second in command to divert the crew across the north side of the gulch toward the river, while the ranger and himself would eat a quick meal.

\section{$5: 40$}

The foreman took is leading position at the beginning of the crew line marching toward the river, when suddenly he saw that the fire had crossed the gulch and was coming straight toward them. The foreman turned the crew away from the coming flames toward a very steep hill covered with high bunch grass. As the fire was moving too fast and the foreman assessed that the crew could not make it in time to the top of the ridge, he yelled at the crew to drop their tools, started to lit an escaper fire in front of them and asked them to join him. No member of the crew followed the instructions. The foreman survived by lying down in the area of his escape fire. 13 members of the crew died few meters away while trying to reach the top of the ridge. 
Figure 1. The succession of critical events in the Mann Gulch disaster

Weick analyzes this case as interactive disintegration of sensemaking, consisting in attempts at gaining a retrospective sense of the ongoing events. According to Weick, when the smokejumpers landed at Mann Gulch, they expected to find an ordinary fire and rationalized on this image till it was too late and this made them engage in actions which made less and less sense:

- They run toward the only visible escape route, instead of joining the foreman, Dodge, lighting a fire right in the middle of this only visible escape route.

- The second in command shouts "To hell with that. I am getting out of here," in response to the foreman's order to join him in using the escape fire as rescue.

- The members of the crew runs to escape from a rapidly advancing fire, instead of following the action of the foreman which does not make sense to them.

In fact the foreman was inventing a new tactic of fighting fire, which after the Mann Gulch disaster was introduced in all basic training of firefighters.

But what do the example of Mann Gulch and the Vygotsky's double stimulation have to do with one another? In spite of their obvious differences, both Mann Gulch disaster and Vygotsky's example of the waiting experiment are situations in which sense collapses, conflicts arise and material resources are mobilized in order to break out of the paralyzing conflict.

"Sensemaking... is built out of ...negotiated agreements that attempt to reduce confusion. People in Mann Gulch did not face questions like where should we go...? Instead, they faced the more basic, the more frightening feeling that their old labels were no longer working. They were outstripping their past experience and were not sure... what was up." (Weick, 1993, p. 636)

While according to Weick what was going on in Mann Gulch was primarily the sensemaking question of "what is this about," these crew members may have been also primarily concerned with the agentive question of "what to do." Within this perspective interpersonal negotiations of agreements and retrospective investment in sensemaking become of secondary importance, if not irrelevant. Instead, forward-oriented search actions and negotiation with the environment take over, especially when there is high time pressure involved. From this point of view, Weick's analysis of the Mann Gulch does not explain the 
prospective initiative of lighting an escape fire by Dodge, the foreman, and the forwardoriented (but self-defeating) actions of the members of the crew who died.

Weick explains Dodge's counterintuitive invention of the escape fire as "improvisation and bricolage." These notions are too vague and abstract to explain what actually happened. But Weick's account does contain indications of what might have been crucial components in a condensed episode of double stimulation carried out by Dodge. Weick points out that Dodge was an experienced woodsman, with lots of hands-on experience.

"And since Dodge had been in the Forest Service longer than anyone else on the crew, he would also have known more fully their four guidelines at that time for dealing with fire emergencies. These included (1) start a backfire if you can, (2) get to the top of a ridge where the fuel is thinner, (3) turn into the fire and try to work through it, and (4) don't allow the fire to pick the spot where it hits you. Dodge's invention, if we stretch a bit, fits all four. It is a backfire, though not in the conventional sense of a fire built to stop a fire. The escape fire is lit near the top of a ridge, Dodge turns into the main fire and works through it by burning a hole in it, and he chooses where the fire hits him. The 15 who tried to outrun the fire moved toward the ridge but by not facing the fire, they allowed it to pick the spot where it hit them." (Weick, 1993, p. 639)

In terms of double stimulation, the initial conflict of motives was: To fight the fire or to run from it in order to escape. On the basis of Weick's observations, we may assume that the four guidelines internalized by Dodge served as a second stimulus that enabled him to overcome the impulse to run and to face the fire by means of lighting an escape fire and lying face down in the ashes. If we had a possibility to reconstruct Dodge's actions and thoughts in detail, we might further discover that a matchbox in his pocket served for Dodge as the crucial material artifact that made the second stimulus alive and real in a situation of extreme pressure.

"He saw that in front was high dry grass that would burn very fast, saw for the first time the top of the ridge ... put two and two together and decided that he and his crew couldn't make the two hundred yards, and almost instantly invented what was to become known as the 'escape fire' by lighting a patch of bunch grass with a gofer match. (...) Dodge was starting to light a second fire with a second match when he looked up and saw that the first fire had already burned one hundred square feet of grass up the slope.” (Maclean, 1992, p. 92-93) 
In existing literature, organizing in situations of uncertainty or crises is seen as primarily dependent on interactive and retrospective sensemaking cycles to which action is subordinated. Instead, organizing may be primarily dependent on willful, materially mediated transformative actions to which sensemaking is subordinated. Sensemaking serves the purpose of acting, not the other way around.

In expansive learning, the object of a collective activity system is expanded so as to open up qualitatively new possibilities of action and emancipation. Driven by historically accumulated contradictions in the activity, such a learning process is lengthy and involves multiple steps, called learning actions (Engeström, 2015; Engeström \& Sannino, 2010).

Dodge's invention happened within a time span of minutes and seconds. So how does it exemplify expansive learning? Obviously Dodge's action of lighting an escape fire was merely a beginning of a lengthy process. As Maclean (1992, p. 92) points out, "in so doing, he started an argument that would remain hot long after the fire." As a result, the Forest Service studied the extreme features of the Mann Gulch fire and revised its training programs and guidelines to include measures such as the escape fire. The conceptualization of the object - forest fire - was expanded.

Transformative agency by double stimulation is a foundational agentive quality of expansive learning. Expansive learning actions are not directly driven by systemic contradictions. The contradictions must be personally experienced as conflicts of motives. The construction of a second stimulus (auxiliary motive) is a key step that sets expansive learning in motion. This involves the appropriation or creation of an artifact that serves as a springboard that allows the learners to break out of the paralyzing conflict. The second stimulus is a starting point for actions of modeling a new, expanded object.

All this typically happens through successive iterations of double stimulation in the process of expansive learning. Thus, instead of a single second stimulus, multiple interconnected artifacts are constructed and employed, gradually forming an instrumentality for the expanded activity. Expansive learning may be depicted as a chain or texture of partly successive, partly parallel and overlapping iterations of double stimulation. The durability and resilience of an expansive learning process stem from these repeated and interlinked iterations. 


\section{Double Stimulation In The Finnish National Program For The Eradication Of Homelessness}

Globally across major wealthy cities often costly initiatives are undertaken to respond to homelessness. A large variety of actors are involved, ranging from informal and grassroots collectives, public and private organizations, political forces as well as educational institutions. Their initiatives, however, seldom lead to impactful concerted efforts. Fragmentation and discoordination often lead to ineffective use of rather substantial economic resources. The Finnish homelessness case, instead, has mobilized resources which are comparatively rather modest. Yet this is the only nation in Europe that has been able to significantly reduce homelessness since the start of a national strategy in 2008. Long-term homelessness in Finland has reduced 36\% since 2008 with $82 \%$ of former homeless maintaining their new homes. A recent study states that "By international standards, Finland is actually close to eradicating homelessness" (Pleace \& Knutagard, 2016, p. 437).

The Finnish homelessness strategy relies on the central principles of Housing First (Sahlman \& Lehtniemi, 2017; Raitakari \& Juhila, 2015), combined with the supply of affordable housing and preventive measures targeted to a population with complex problems and high need of social and health care services. The strategy is implemented by building new housing units and converting existing buildings used for temporary and emergency shelter accommodations into independent supported housing units.

One of the key resources on which the Finnish strategy relies is the Finnish welfare model which has been characterized as the most "de-commodified" (Espin-Andersen, 1990) welfare model, guaranteeing access to social benefits by right rather than by status or contributions (Kuisma, 2017). Another resource on which the Finnish strategy relies is the input from the strong third sector characteristic of Finnish society with a wide range of nonprofit organizations and volunteer work.

The Finnish homelessness strategy is a heavy critique of and an alternative to the traditional staircase model, according to which a client first must overcome addictions and other problems and only then can have a home. The Finnish model instead emphasizes commitment on the part of the institutions and the clients, as well as tailored solutions to meet specific and evolving needs of the client. This approach has received heavy criticism and has in same cases be considered nonsensical. The Housing First principle is often ironically referred to as "bottle first," pointing to the housing units in which the use of 
alcohol is allowed. Resistance from workers for this reason has been seen as one of the core challenges of learning and agency over the past ten years.

The following account was written by a social work supervisor in one of the newly established housing units within the homelessness strategy (Pyyvaara \& Timonen, 2017). The account is an illustration of what the breaking out of the standard staircase procedures entails - its realistic risks and the negative reactions it attracts.

"When the unit opened in 2013, many of the tenants had an history of attempts to live in various kinds of housing services in which the living had often ended because of breaking the rules (on drugs or alcohol which were strictly forbidden in these units) or because the tenants had been out of the reach of the support services.

At the beginning the contents of the housing service were explained several times to the inhabitants, including the fact that the client can return home under the influence of drugs or alcohol and be there without the risk of being evicted. This was a big thing especially for those clients who had been kicked out from other units for this very reason. They experienced the coming to Pähkinärinne (housing unit) as coming of adult age, even though their age was between 40 and 6o. ... The new coming of age became visible at the beginning of the functioning of the unit in a negative way, in the form of some inhabitants' long continuous drinking and worsening of their physical condition...

At the beginning drinking increased, enforcing negative attitudes toward the Housing First principle applied in this unit. ...

I claim that it is actually totally impossible to create permanent and complete alcohol-free solutions specifically for addicts. ... We need to focus on making sure that the clients, when they need it, will get addiction care and tools for living and getting along in a society which does include alcohol and actually encourages its 
use. They need to learn to live either without alcohol or at least without the severe consequences of alcohol, meaning that the alcohol use is under control."

The housing units created within the strategy in which the tenants are allowed to use drugs and alcohol are often exposed to criticism as a nonsense. Yet, the $82 \%$ retention rate mentioned above, is an indication that this is far from an ill-conceived attempt to eradicate homelessness. Tangled up between already consolidated modes of actions and new demands from the strategy, all the actors involved in eradicating homelessness in Finland must learn and establish new modes of action.

Frontline workers in the housing units, must learn ways to support clients with an history of homelessness and multiple interlinked socio-economic, health- and addictionrelated issues in a journey toward a functional independent living in a home of their own. For the housing unit clients this learning involves self-designed and self-enforced (rather than classic behaviouristic) conditioning which builds up into novel modes of actions that serve the development of individual clients and their life activity. The clients in the housing units may experience conflicts of stimuli between the sensation of autonomy in their newly acquired rental apartment and the tempting availability of alcohol and drugs. This conflict of stimuli commonly translates into a conflict of motives (first stimulus) between the motive of living a healthy life in one's own home on the one hand and the motive of continuing a lifestyle of substance abuse which deteriorates one's own condition and puts at risk the possibility of a new beginning on the other hand. The rental agreement and the negotiated care plan document serve as second stimuli for the clients to build their agency and learn a new way of living. The difficult step toward this end consists in sticking to the contents of these agreements, for instance by paying the rent each month instead of using the money to buy drugs and alcohol.

The expansive learning and transformative agency cycles of the individual client and the frontline workers lead to qualitative transformations in the life of the client as well as in the work of the professionals across the coalition.

"Kalle comes, calls the councelor and the youth station and agrees on appointments.

January rent has not been paid and we make a payment plan for it because there is not money at the moment. Kalle wishes that we can meet regularly, he feels he needs support. Toward the end of March the rental agreement is renewed. We make a 
continuation agreement for one year, upon Kalle's request. [...] Next March, we have

a network meeting with Kalle and he gets a rental agreement without fixed termination time.” (Account of the situation of client Kalle, in Pyyvaara \& Timonen, 2017, p. 52)

By repeating over and again the double stimulation steps, the clients' transformative agency emerges and develops. Essentially this is a deliberately initiated conditioning process by the frontline workers and eventually adopted by the clients. Both parties by means of these agreements resolve to learn respectively a new way of sensemaking, working and living. It is conceivable that the self-confidence gained by reaching control over alcohol abuse, for instance, may lead also to gaining control over other problem areas in the lives of these clients, for instance by finding and maintaining a job and paying one's debts. At the same time the client's learning process contributes to the construction of new, wider and more complex knowledge in the frontline workers' activities, the activity of the housing unit as a whole, and the other nodes of the organizing effort within the strategy.

\section{Conclusion: Expansive Organizational Learning In The Finnish Homelessness Strategy}

Long-term homelessness is prolonged living without one's own home due to socioeconomic, health- and addiction-related problems. As such it is a web of multiple conditions which is considered a top indicator of poverty associated with extreme social exclusion and vulnerability. A problem like this requires a peculiar organizational form that we call heterogeneous work coalitions.

Merriam-Webster's dictionary defines coalition as "a temporary alliance of distinct parties, persons, or states for joint action." In other words, a coalition is formed to accomplish coordinated actions for a common purpose. This dynamically purpose-oriented and temporary nature makes a coalition different from the much more stable, if not static, notion of organizational fields, defined by DiMaggio and Powell (1983, p. 148) as "sets of organizations that, in the aggregate, constitute a recognized area of institutional life; key suppliers, resource and product consumers, regulatory agencies, and other organizations that produce similar services or products." Actors become members of a coalition by 
deliberate decision and commitment; they may be members of a field without even knowing it.

The heterogenous work coalition of the Finnish national strategy for the eradication of homelessness may be depicted with the help of Figure 2.

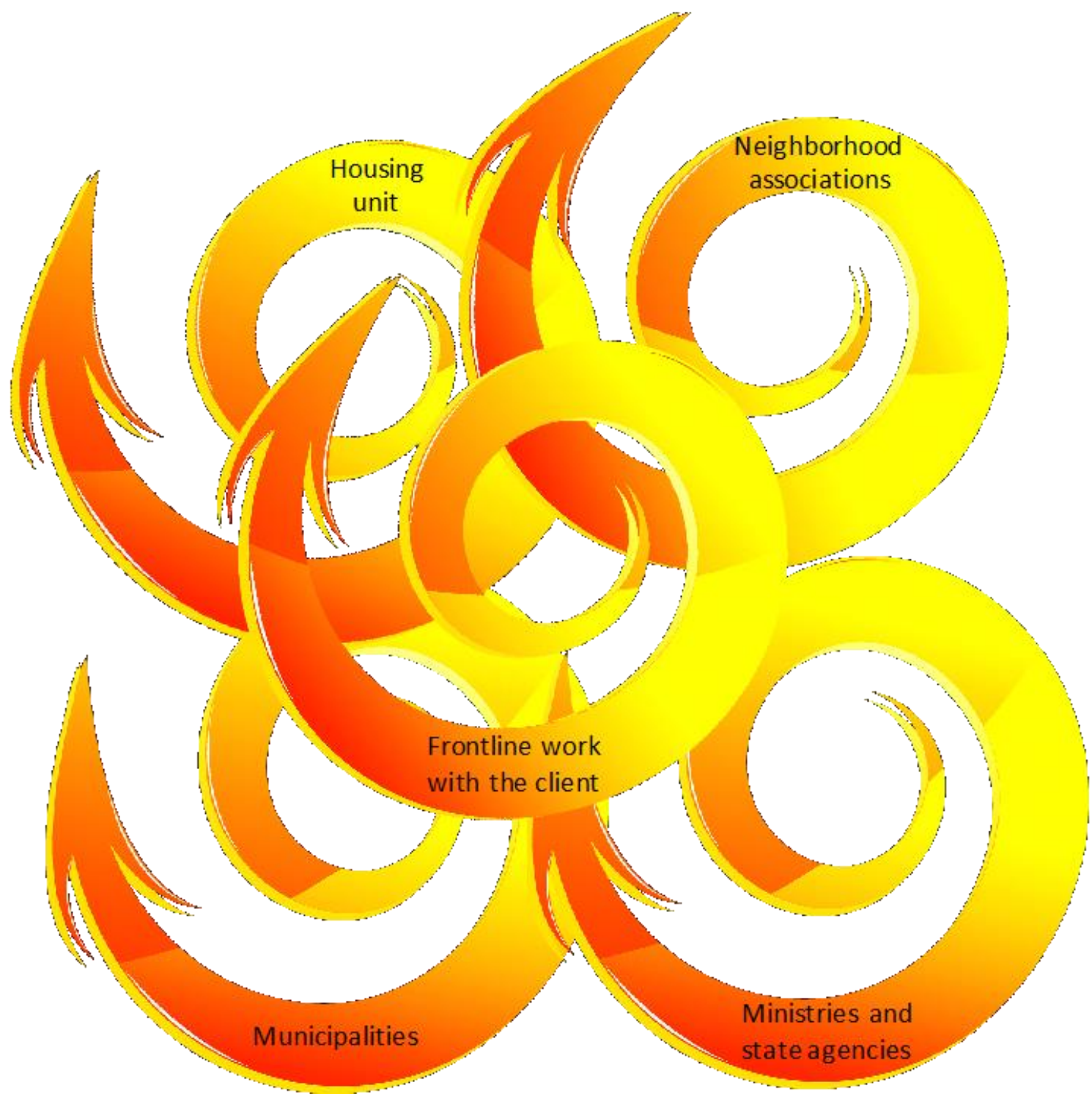

Figure 2. The heterogenous work coalition of the Finnish homelessness strategy as intertwined cycles of expansive organizational learning

The expansive learning process in this coalition consists of multiple interacting and overlapping cycles which are both relatively independent and interdependent. They require one another to emerge and sustain themselves. They also operate across sectors and at different hierarchical levels in the society. By interweaving the learning cycles of the 
different actors, from individual clients and their frontline support workers to housing units, NGOs, ministries and municipalities, this kind of a heterogeneous coalition effectively transcends the dichotomy of organizational vs. individual learning, as well as more nuanced versions on multiple levels of learning (Wiewiora, Smidt \& Chang, 2018).

Once the contact between the client and one of the key frontline services in the coalition is established, a long chain of further work can start. This work is a learning journey toward the unknown. This learning goes beyond the acquisition of well-established sets of knowledge and the participation in relatively stable practices. Each client has a specific constellation of issues to address which require supportive interactions and tailored solutions co-designed with the client, and changing as the client progresses or regresses. What is peculiar of these intertwined learning processes is their strong agentive nature. It is work made of tailored concerted efforts by a flexibly developing work coalition pursuing one and the same motive and purpose: the functional independent living of the client in a home of his or her own.

Double stimulation in these learning processes relies largely on agreements and negotiated plans in similar ways as in the stepwise process described above for the frontline workers and the clients. The agreements and plans are established and systematically used as second stimuli. Letters of intent have been signed between the state and each involved municipality. For example, the letter of intent between the state and the City of Helsinki for 2012-2015 is a document that details six concrete measures to be undertaken, starting with the exact numbers of dwellings or homes in supported housing units to be provided for longterm homeless clients. The letter of intent begins as follows.

"The purpose of this letter of intent between the state and the City of Helsinki is to eradicate long-term homelessness through common actions by the state and the municipalities. Similar letters of intent have been drawn up with the cities of Espoo, Vantaa, Tampere, Turku, Joensuu, Kuopio, Lahti, Oulu, and Jyväskylä. ... The letters of intent create the preconditions ensuring that by 2015 it will be possible to allocate, at least, 1250 dwellings, supported dwellings or places in sheltered housing ... to the long-term homeless. Of the dwellings, 750 will be allocated to Helsinki and a total of 250 to Espoo and Vantaa. ...The letters of intent are used to define the participation of the parties to the agreement in implementing the measures. ..." (Sahlman \& Lehtniemi, 2017, p. 112)

The letters of intent are reviewed and, if needed, revised annually. This is an example of recurring iterations of double stimulation in this constellation of expansive learning. By 
means of these documents the agency of the coalition as a whole is built by grounding it in specific local commitments.

Supported housing units, run by NGOs and funded by the municipalities, play a key role in the strategy. One of these units is called Väinölä.

"When moving into Väinölä [a supported housing unit in the city of Espoo], each resident signs a support contract along with the lease. In it, the resident agrees to strive towards a substance-free lifestyle if that has been a problem for them and to make themselves a service plan together with the staff.” (Sahlman \& Lehtniemi, 2017, p. 39)

"A service plan is made for each resident with the purpose of supporting the resident towards goal-oriented action and life management. It is made in cooperation with the resident, floor counsellors and a social worker. The plan is updated at least every six months. In addition to life management, the plan helps staff provide the kind of guidance and support that the resident needs.” (Sahlman \& Lehtniemi, 2017, p. 52)

Notice here again the recurring iterations of double stimulation. "The plan is updated at least every six months."

The ten years of the Finnish homelessness strategy indicate the potential of these learning and agency processes to become dense patterns with grounding and resilience to withstand resistance to what might seemingly appear as nonsensical initiatives. The expansive learning process is going on simultaneously in so many activities that troubles or failures in one setting are compensated and overcome by support from other settings. These supportive actions of relational and horizontal "sideways learning" among actors that may formally represent quite different hierarchical positions need to be further documented and analyzed. 


\section{References}

Antaki, C. (1994). Explaining and arguing: The social organization of accounts. London: Sage Publications.

Christianson, M. K., \& Sutcliffe, K. M. (2009). Sensemaking, high-reliability organizing, and resilience. In P. Croskerry, K. S. Cosby, S. M. Schenkel, \& R. L. Wears (Eds.). Patient safety in emergency medicine (pp. 27-33). Philadelphia, PA: Lippincott Williams \& Wilkins.

DiMaggio, P., \& Powell, W. W. (1983). The iron cage revisited: Collective rationality and institutional isomorphism in organizational fields. American sociological review, 48(2), 147-160.

Engeström, Y. (2015). Learning by expanding: An activity-theoretical approach to developmental research. (2. ed.). Cambridge: Cambridge University Press.

Engeström, Y., \& Sannino, A. (2010). Studies of expansive learning: Foundations, findings and future challenges. Educational Research Review, 5(1), 1-24.

Engeström, Y. \& Sannino, A. (2016). Expansive learning on the move: Insights from ongoing research. Infancia y Aprendizaje: Journal for the Study of Education and Development, 39(3), 401-416.

Esping-Andersen, G. (1990). The three worlds of welfare capitalism. Cambridge: Polity.

Gephart, R. P., Topal, C., \& Zhang, Z. (2010). Future-oriented sensemaking: Temporalities and institutional legitimation. In T. Hernes \& S. Maitus (Eds.). Process, sensemaking, and organizing (pp. 275-312). Oxford: Oxford University Press.

Isabella, L. A. (1990). Evolving interpretations as a change unfolds: How managers construe key organizational events. Academy of Management Journal, 33(1), 7-41.

Kaplan, S., \& Orlikowski, W. J. (2013). Temporal work in strategy making. Organization Science, 24(4), 965-995.

Kuisma, M. (2017). Oscillating meanings of the Nordic model: Ideas and the welfare state in Finland and Sweden. Critical Policy Studies, 11(4), 433-454. 
Maitlis, S. (2005). The social processes of organizational sensemaking. Academy of Management Journal, 48, 21-49.

Maitlis, S., \& Christianson, M. (2014). Sensemaking in organizations: Taking stock and moving forward. The Academy of Management Annals, 8(1), 57-125.

Maclean, N. (1992). Young men and fire. Chicago: University of Chicago Press.

Orton, J. D. (2000). Enactment, sensemaking and decision making: Redesign processes in the 1976 reorganization of US intelligence. Journal of Management Studies, 37(2), 213234 .

Pleace, N., Knutagård, M., Culhane, D. P., \& Granfelt, R. (2016). The strategic response to homelessness in Finland: Exploring innovation and coordination within a national plan to reduce and prevent homelessness. Exploring effective systems responses to homelessness, 426-442.

Pyyvaara, U. \& Timonen, A. (Eds.). (2017). Naamat (Faces). Helsinki: Into.

Raitakari, S., \& Juhila, K. (2015). Housing First literature: different orientations and political-practical arguments. European Journal of Homelessness, 9(1), 145-189.

Sahlman, E. \& Lehtniemi, N. (2017). Housing First and ending homelessness in Finland. Helsinki: Y-Säätiö.

Sannino, A. (2015). The principle of double stimulation: A path to volitional action. Learning, Culture, and Social Interaction, 6, 1-15.

Sannino, A. \& Engeström, Y. (2016). Relational agency, double stimulation and the object of activity: An intervention study in a primary school. In A. Edwards (Ed.). Working relationally in and across practices: Cultural-historical approaches to collaboration (pp. 58-77). Cambridge: Cambridge University Press.

Sannino, A., Engeström, Y., \& Lemos, M. (2016). Formative interventions for expansive learning and transformative agency. Journal of the Learning Sciences, 25(4), 599-633. 
Sannino, A. \& Laitinen, A. (2015). Double stimulation in the waiting experiment: Testing a Vygotskian model of the emergence of volitional action. Learning, Culture, and Social Interaction, 4, 4-18.

Taylor, J. R., \& Van Every, E. J. (2000). The emergent organization: Communication as its site and surface. Mahwah, NJ: Erlbaum.

Vygotsky, L. S. (1997). The history of development of higher mental functions, Chapter 12: Self-control. In R. W. Rieber (Ed.). The collected works of L.S. Vygotsky, (v. 4): The history of the development of higher mental functions (pp. 261-281). New York: Plenum.

Weick, K. E. (1979). The social psychology of organizing (2. ed.). New York: McGraw-Hill.

Weick, K. E. (1988). Enacted sensemaking in crisis situations. Journal of Management Studies, 25(4), 305-317.

Weick, K. E. (1993). The collapse of sensemaking in organizations: The Mann Gulch disaster. Administrative Science Quarterly, 38(4), 628-652.

Weick, K. E. (1995). Sensemaking in organizations. Thousand Oaks, CA: sage Publications.

Weick, K. E. (2003). Positive organizing and organizational tragedy. In K. S. Cameron, J. E. Dutton, \& R. E. Quinn (Eds.), Positive organizational scholarship: Foundations of a new discipline (pp. 66-80). San Francisco, CA: Berrett Koehler.

Weick, K. E., Sutcliffe, K. M., \& Obstfeld, D. (2005). Organizing and the process of sensemaking. Organization Science, 16(4), 409-421.

Whiteman, G., \& Cooper, J. B. (2011). Ecological sensemaking. Academy of Management Journal, 54(5), 889-911.

Wiebe, E. (2010). Temporal sensemaking: Managers' use of time to frame organizational change. In T. Hernes \& S. Maitlis (Eds.), Process, sensemaking, \& organizing (pp 213241). Oxford: Oxford University Press.

Wiewiora, A., Smidt, M., \& Chang, A. (2018). The 'how' of multilevel learning dynamics: A systematic literature review exploring how mechanisms bridge learning between 
Teoria e Prática em Administração, volume 8, número 2 (special issue), ano 2018 Valuable Innovations out of Nonsense? Expansive Organizational Learning and Transformative Agency in the Mann Gulch Disaster and in the Finnish Homelessness Strategy
Sannino \& Engeström Sannino \& Engeström
p. $60-79$

DOI: http://dx.doi.org/10.21714/2238-104X2018v8i2S-40728 Submission: Abr/08/18 -Second version: Ju/10/18 - Acceptance: Jul/11/18

individuals, teams/projects and the organization. European Management Review. DOI:

10.1111/emre.12179 